\title{
Experimental and Analytical Investigation of Column- Beam Joints with Smart Frame Based on Strain Compatibility
}

\author{
Yeo-Jin Yun, Won-Kee Hong, Sunkuk Kim, and Jeong Tai Kim
}

\begin{abstract}
A great deal of research is being carried out on dry and prefabricated construction methods with a precast composite structural system. This study investigates the joint behavior and calculates structural capacity of a Smart frame, which is a steel-reinforced concrete structural system developed by researchers in a structural experiment. The structural experiment discovered that flexural moment capacity improved by $46.8 \%$ in Smart columns compared to reinforced concrete columns. This study is expected to contribute to structural design.
\end{abstract}

Index Terms-Joint, precast composite structural system, smart frame, strain compability, structural experiment joint.

\section{INTRODUCTION}

Currently many studies on the precast composite structural system which is easy to reassemble/disassemble on the site are underway.

Chou et al. conducted an experiment to evaluate the cyclic performance with two exterior moment connections which consisted of a steel-encased reinforced concrete column and a steel beam [1]. Jafarian et al. used numerical models to study the seismic behavior of the hybrid-steel concrete connection. The critical parameters influencing the joint's behavior and the axial load on the column are varied, and their effects were studied [2]. Ju et al. proposed a composite beam and conducted an experiment using a series of monotonic loading tests. The results show that the capacity of the proposed system agrees with design code predictions, and the system demonstrates a reliable composite behavior between the steel beam and the concrete slab [3].

Fig. 1 shows various types of composite column joints developed by preceding studies [4], [5]. Steel joints are installed at the end of the column where the beam connect for easy and simple connection. However, there are few studies on the structural performance of steel joints. Thus, this experimental research was conducted to identify the structural performance of composite column with steel joints

Manuscript received June 14, 2014; revised July 26, 2014

The authors are with the Dept. of Architectural Engineering, Kyung Hee Univ., 1732 Deogyeong-dearo, Giheung-gu, Yongin-si, Gyeonggi-do, Korea (e-mail: yunyj@khu.ac.kr, hongwk@khu.ac.kr,kimskuk@khu.ac.kr jtkim@khu.ac.kr)
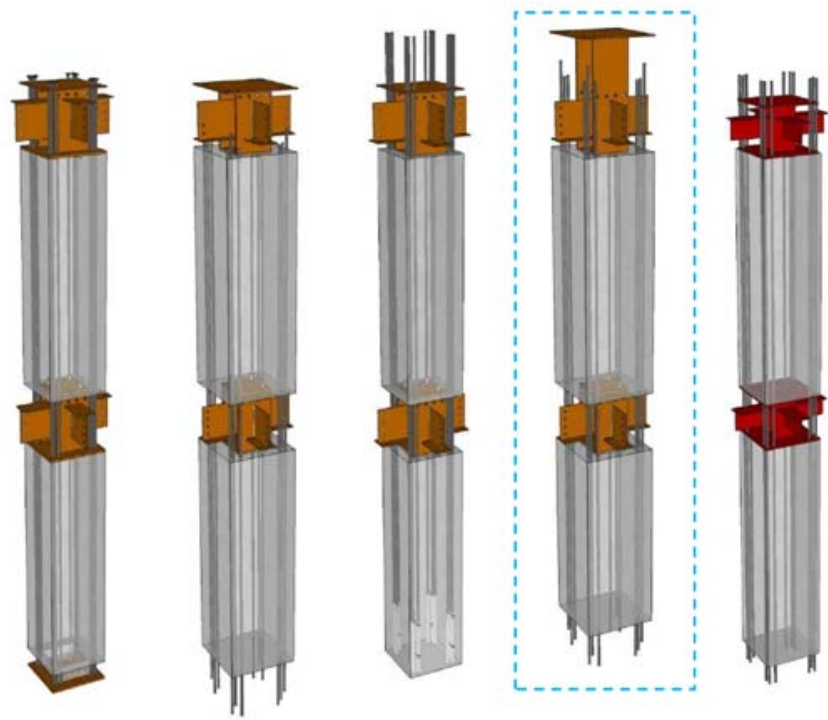

Fig. 1. Types of composite column with smart frame.

\section{SMART FrAmE}

The Smart frame developed by Hong et al. consists of structural tees, reinforcement steels, and pre-cast concrete. Previous research has demonstrated the advantages of the Smart frame as follows:

- The Smart frame is based on semi-dry construction methods; this reduces the construction schedule, minimizes the use of temporary materials, and leads to savings in embodied energy [6].

- This method also provides solutions for the floor height of apartment buildings with a reinforced concrete Rahmen frame and demonstrates its structural and economic efficiency and constructability through tests and simulations [7], [8].

- This structural system provides a level of architectural flexibility that is not offered by a conventional bearing-wall structure and maximizes the efficiency of material use [9].

\section{EXPERIMENT}

\section{A. Experiment Design}

To examine the structural performance and behavior of composite column joints, this study performed a series of cyclic loading tests for three specimens. As shown in Fig. 2, the length and placement of steels were used as variables to investigate the effect on a steel frame. 

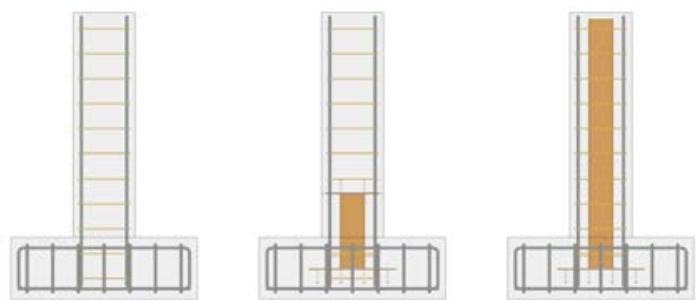

Fig. 2. Test specimens.

Fig. 3 shows the test set-up and specimen ready for the loading application. The bottom was set as a fixed end to allow specimens to act as a cantilever. The height from the fixed end to a loading point was $1.5 \mathrm{~m}$. Three specimens were subjected to cyclic loading using the oil jack. A displacement control method was adopted as a loading protocol for this experiment.

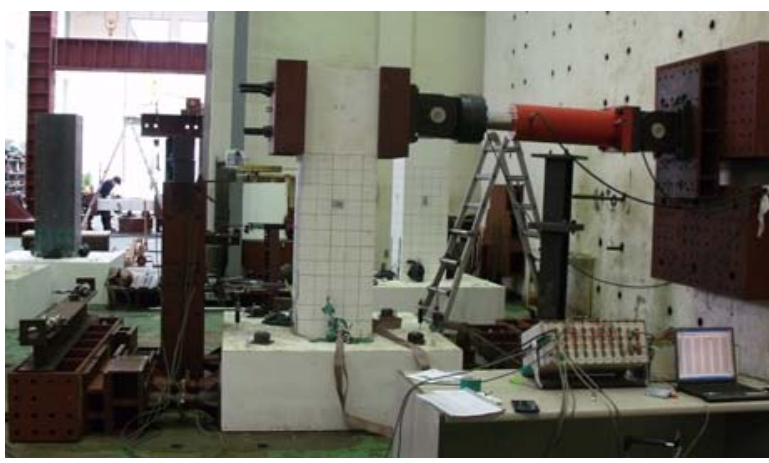

Fig. 3. Installation of specimens.

TABLE I: EXPERIMENTAL PARAMETERS

\begin{tabular}{cccc}
\hline \hline \multirow{2}{*}{ Specimen } & \multicolumn{3}{c}{ Parameters } \\
& Reinforcement & \multicolumn{2}{c}{ Steel Section } \\
\hline$\# 1$ & 4-HD25 & - & - \\
$\# 2$ & $4-H D 25$ & H-200X200X8X12 & Partial span \\
$\# 3$ & 4-HD25 & H-200X200X8X12 & Entire span \\
\hline \hline
\end{tabular}

\section{B. Experimental Parameters}

Concrete of 27Mpa, wide flange steel of SM400, and reinforcement of SD400 were used. For specimens \#2 and $\# 3$, stud bolts of SS400 with a $22-\mathrm{mm}$ diameter and $150-\mathrm{mm}$ length were installed in steel frames and reinforcing plates. Specific parameters are shown in Table I.

\section{Experiment Results}

1) Loading-displacement curve

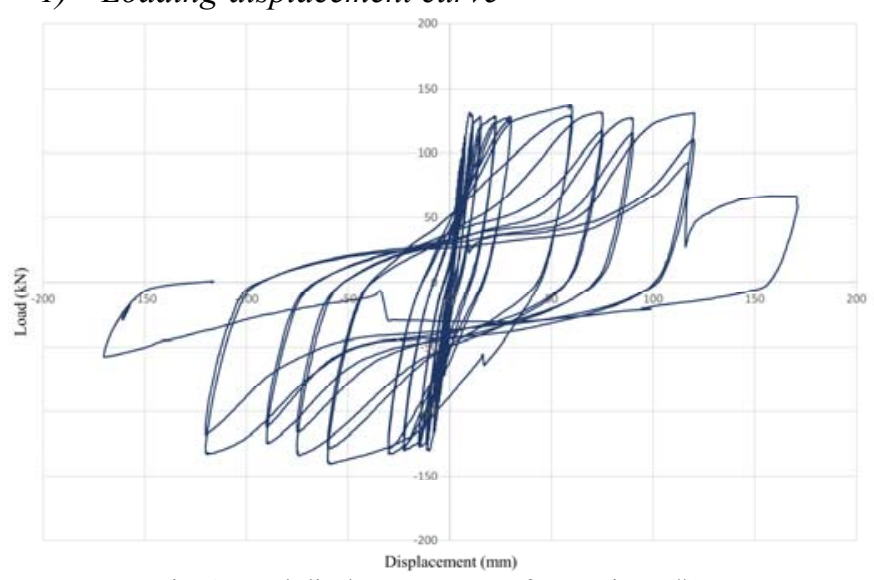

Fig. 4. Load-displacement curve for specimen \#1.

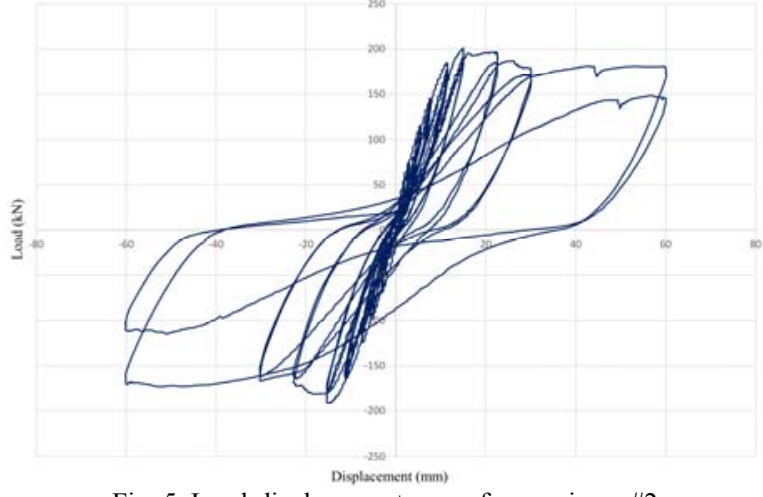

Fig. 5. Load-displacement curve for specimen \#2.

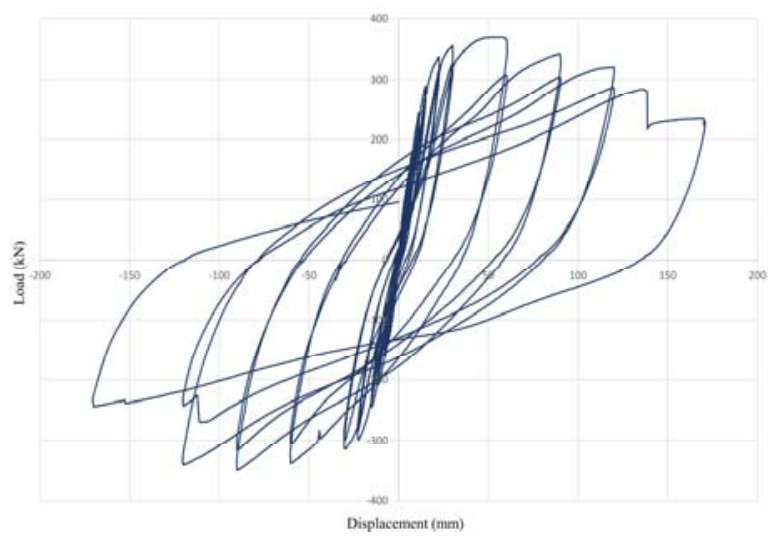

Fig. 6. Load-displacement curve for specimen \#3.

Fig. 4-Fig. 6 show the load-displacement hysteresis curves. For specimen $\# 1$ and $\# 2$, the load at the maximum load limit state was $136.8 \mathrm{kN}$ and $200.92 \mathrm{kN}$, respectively. For specimen $\# 2$, the spot $650 \mathrm{~mm}$ from the end ruptured as the concrete cover spalled where the steel plate was embedded $350 \mathrm{~mm}$ from the end. For specimen \#3, the load at the maximum load limit state was $361.79 \mathrm{kN}$, and it was destroyed as the tensile reinforcement broke.

2) Load-strain curve

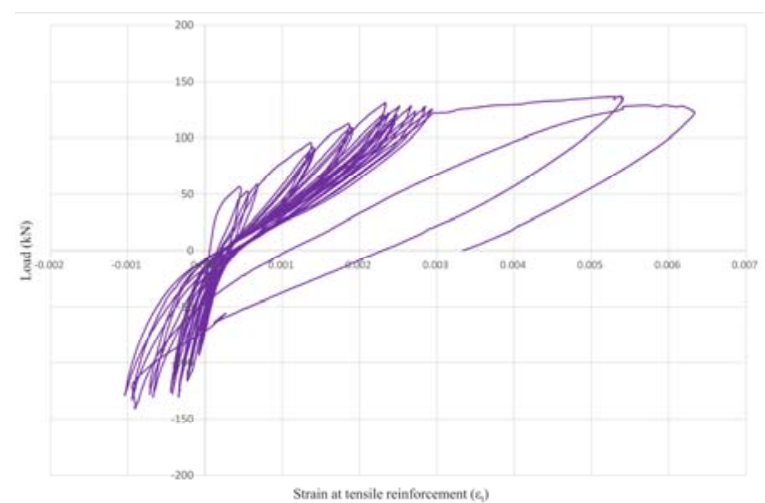

Fig. 7. Load-strain curve of the tensile reinforcement of specimen \#1.

Fig. 7-Fig. 9 demonstrates the load-strain hysteresis curves of the tensile reinforcement. For specimen \#1, the strain rate of steel reinforcement at the maximum load limit state was 0.00536 . For specimen $\# 2$, the strain rate of steel reinforcement at the maximum load limit state was 0.00567 , but as the concrete cover spalled, the load reduced to $75 \%$ of the maximum load when displacement control to reach $60 \mathrm{~mm}$. For specimen \#3, the strain rate of steel reinforcement at the maximum load limit state was 0.008527 . 


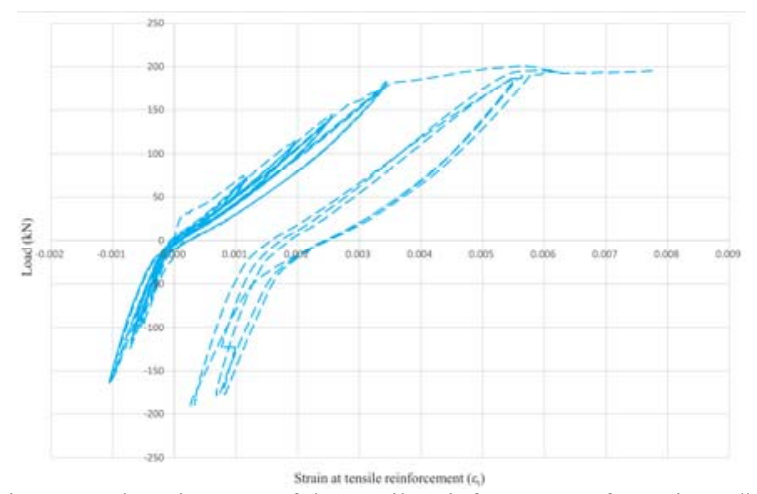

Fig. 8. Load-strain curve of the tensile reinforcement of specimen \#2.

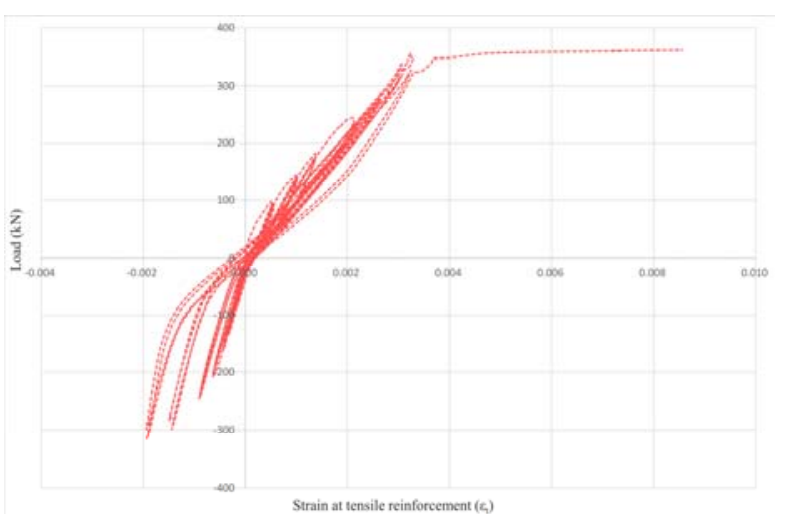

Fig. 9. Load-strain curve of the tensile reinforcement of specimen \#3.

\section{ANALYSIS BASED ON STRAIN COMPATIBILITY}

Strain compatibility analysis is used to predict the behavior of composite members by linearizing the strain of the composite section. The next step is to determine the strain compatibility of the compressed concrete upper section and the assumed neutral axis. The equilibrium equation with a proportional expression is used for the neutral axis, and can be applied to calculate the neutral axis value [10].

The behavior of composite members can be defined and classified into 4 different limit states as shown in Table II and Fig. 10 [11].

TABLE II: DEFINITION OF THE LiMit STATE

\begin{tabular}{cc}
\hline Limit State & Definition \\
\hline $\begin{array}{c}\text { Pre-yield } \\
\text { Yield }\end{array}$ & $\begin{array}{c}\text { Prior to the yield limit state } \\
\text { The load at which the tensile reinforcement yields } \\
\text { The load at which the compressive concrete strain } \\
\text { reaches } 0.003\end{array}$ \\
Failure & The load corresponding to failure \\
\hline \hline
\end{tabular}

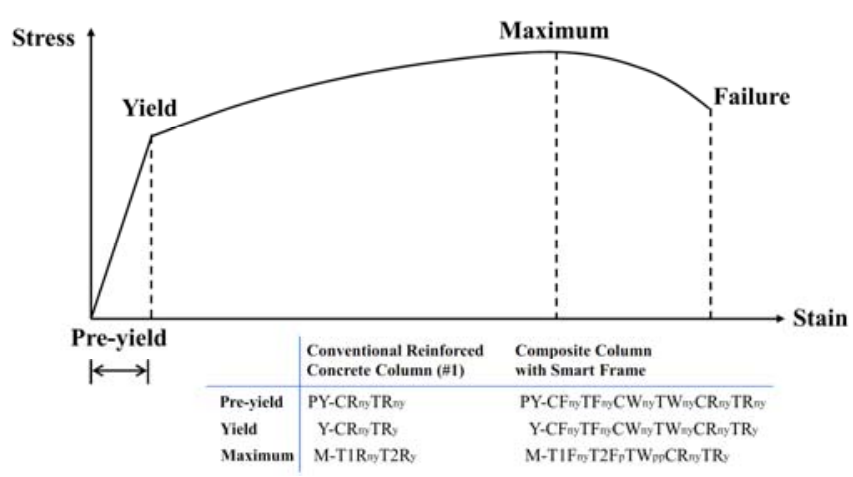

Fig. 10. Stress distribution assumptions at each limit state.
The performance reports of reinforcement steel and wide flange steel, and experimental results for the concrete were utilized to analyze and calculate. The compressive strength of concrete was $28.1 \mathrm{MPa}$, and the yield stress of reinforcement steel and wide flange steel were $454 \mathrm{MPa}$ and $325 \mathrm{MPa}$, respectively.

\section{A. Reinforced Concrete Column}

The right assumption at the yield limit state was demonstrated by $Y-C R_{n y} T R_{y}$, and the neutral axis was $99.55 \mathrm{~mm}$. The strain rate of compressive concrete was 0.000668 , and the nominal moment was $184.1 \mathrm{kN}-\mathrm{m}$.

At the maximum load limit state, the right assumption was $M-T 1 R_{n y} T 2 R_{y}$, and the neutral axis is located at $53.43 \mathrm{~mm}$ between the compressive reinforcement and concrete surface. The strain rate of the tensile reinforcement was 0.0215 , and the nominal moment was $195.19 \mathrm{kN}-\mathrm{m}$.

\section{B. Composite Column with Smart Frame}

The right assumption at the yield limit state was found as $Y-C F_{n y} T F_{n y} C W_{n y} T W_{n y} C R_{n y} T R_{y}$, and the neutral axis was $162.46 \mathrm{~mm}$ on the web. The strain rate of tensile reinforcement corresponded to the yield strain rate; here the strain rate of concrete was 0.00134 . The nominal moment was $422.13 \mathrm{kN}-\mathrm{m}$.

The right assumption at the maximum load limit state was $M-T 1 F_{n y} T 2 F_{p} T W_{p p} C R_{n y} T R_{y}$, and the neutral axis was $139.13 \mathrm{~mm}$ between the compressive flange and compressive reinforcement. The strain rate of tensile reinforcement was 0.00644 , and the nominal moment was $492.5 \mathrm{kN}-\mathrm{m}$.

\section{Comparative Analysis}

Fig. 11 shows a load-displacement curve for specimens $\# 1$, \#2, and \#3, as well as calculated values. As for the maximum load of specimen \#1, the experimental value was $136.8 \mathrm{kN}$ and the analyzed value was $130.1 \mathrm{kN}$, presenting about $4.9 \%$ of errors. For the maximum load of specimen \#3, the experimental value was $361.79 \mathrm{kN}$ and the analyzed value was $328.3 \mathrm{kN}$, representing an error of $9.2 \%$. The maximum load of specimen \#3 was $200.92 \mathrm{kN}$, which implies that flexural performance improved by $46.8 \%$ compared to that of the reinforced concrete column.

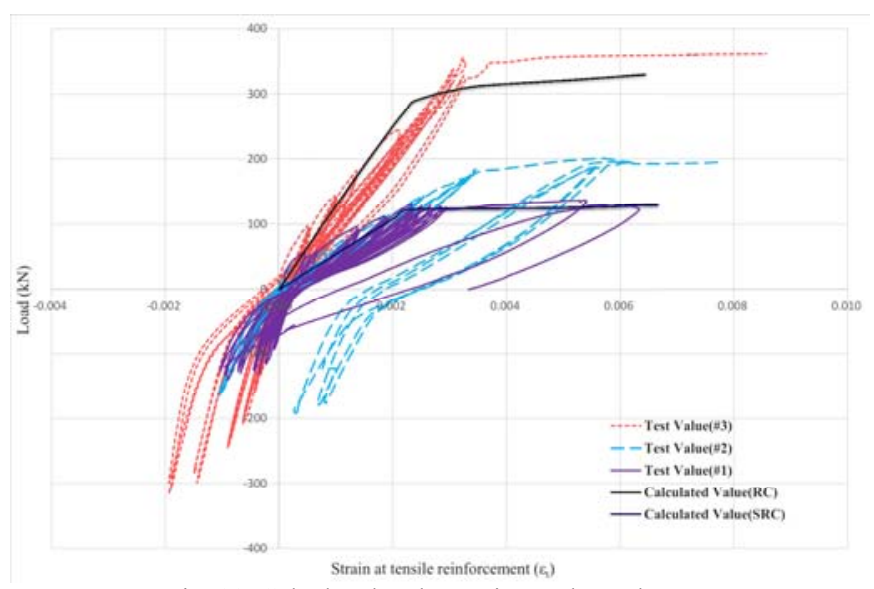

Fig. 11. Calculated and experimental envelopes.

\section{CONCLUSION}

This study conducted an experimental investigation on 
composite columns with the Smart frame to verify the structural performance of steel joints. Based on the comparative results using a strain compatibility approach, the following conclusions were drawn:

- For specimen \#1 which is a conventional reinforced concrete column, its maximum load at the maximum load limit state was $136.8 \mathrm{kN}$. Compared to the analyzed value of $130.1 \mathrm{kN}$, it represents an error of $4.9 \%$.

- For specimen \#3 which is placed in the whole section of the steel frame, the maximum load at the maximum load state was $361.79 \mathrm{kN}$. Compared to the calculated value of $328.3 \mathrm{kN}$, it represents an error of $9.2 \%$.

- For specimen 2 where part of the steel frame is placed at the end, the maximum load was $200.92 \mathrm{kN}$ which is between the values of specimens \#1 and \#3. Compared to specimen $\# 1$, the flexural performance improved by $46.8 \%$. Accordingly, it is believed to have contributed to the bending moment of the end of the stud bolts connected to the steel frame and steel plate.

Consequently, we recommend further analysis study of the impacts of stud bolts installed inside the composite column with a Smart frame using a strain compatibility approach, and exploration of how to reflect it in structural design.

\section{ACKNOWLEDGMENT}

This work was supported by the National Research Foundation of Korea (NRF) grant funded by the Korea government (MSIP) (No.2008-0061908).

\section{REFERENCES}

[1] C. C. Chou and C. M. Uang, "Effects of continuity plate and transverse reinforcement on cyclic behavior of SRC moment connections," Journal of Structural Engineering, pp. 96-104, January 2007.

[2] H. Jafarian and K. Bargi, "Nonlinear seismic behavior evaluation of ductile beam-column connection in precast concrete," Civil and Structural Engineering, vol. 2, pp. 445-453, November 2011.

[3] Y. K Ju and S. D. Kim, "Structural behavior of alternative low floor height system using structural "tee," half precast concrete, and horizontal stud," Canadian Journal of Civil Engineering, vol. 32, pp. 329-338, 2005.

[4] W. K. Hong, S. C. Park, S. Y. Jeong, G. T. Lim, and J. T. Kim, "Evaluation of the energy efficiencies of pre-cast composite columns," Indoor and Built Environment, vol. 21, pp. 176-183, July 2011.

[5] S. H. Lee, J. K. Joo, J. T. Kim, and S. K. Kim, "An Analysis of the $\mathrm{CO}_{2}$ reduction effect of a column-beam structure using composite precast concrete members," Indoor and Built Environment, vol. 21, pp. 150-162, July 2011.

[6] W. K. Hong, D. Y. Yune, S. C. Park, and T. H. Yoon, “An assessment of the energy and resource-efficient hybrid composite beams for multi-residential apartments," Indoor and Built Environment, vol. 20, pp. $148-155$, October 2010.

[7] W. K. Hong, S. C. Park, H. C. Lee, J. M. Kim, S. I. Kim, S. G. Lee, and K. J. Yoon, "Composite Beam Composed of Steel and Precast Concrete (Modularized Hybrid System). PART III: Application for a 19-Storey Building," The Structural Design of Tall and Special Buildings, vol. 19, pp. 679-706, 2009.
[8] W. K. Hong, G. T. Lim, S. C. Park, and J. T. Kim, "Energy efficiencies of linear-shaped multi-residential apartment buildings built with hybrid structural systems," Energy and Buildings, vol. 46, pp. 30-36, 2012

[9] W. K. Hong, S. Y. Jeong, S. C. Park, and J. T. Kim, "Experimental investigation of an energy-efficient hybrid composite beam during the construction phase," Energy and Buildings, vol. 46, pp. 37-47, 2012.

[10] Seismic Design Manual, American Institute of Steel Construction Inc. and the Structural Steel Educational Council, AISC, 2006

[11] J. H. Kim, W. K. Hong, S. C. Park, G. T. Kim, H. J. Ko, and J. T. Kim, "An assessment of $\mathrm{CO}_{2}$ emission of the structural composite hybrid beam based on strain compatibility," Indoor and Built Environment, vol. 22, pp. 117-130, October 2012.

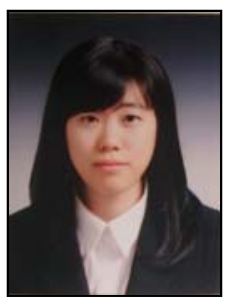

Yeo-Jin Yun is currently seeking master's degree in structural engineering at the Department of architectural Engineering. She has concentrated on various areas of research such as hybrid composite structures, vertical extension remodeling for buildings, pre-cast pre-stressed structural members,

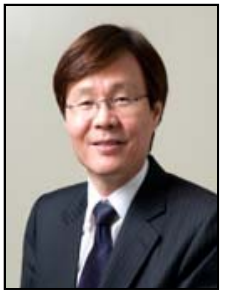

Sunkuk Kim majored in construction engineering and management. He has concentrated on various areas of research such as health performance assessment of buildings, construction technology, project management, simulation and optimization for decision making, construction information technology.

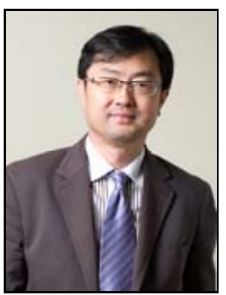

Won-Kee Hong received his master and Ph.D degree from UCLA. He also has professional engineering license from both Korea and U.S.A. Professor Hong's research interests include a new approach to construction technologies based on value engineering and composite structures. He provided many useful solutions to the current structural design and construction technologies issues.

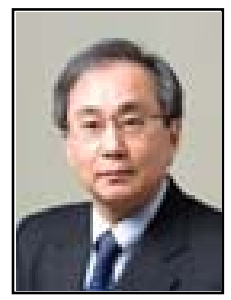

Jeong Tai Kim is a Kyung Hee Distinguished Fellow at Kyung Hee University and is a fellow of the Korea Academy of Science and Technology (KAST). In September of 2008, He founded the center for sustainable healthy buildings $(\mathrm{CSHeB})$ with the award of engineering research center (ERC) from Korea Government. As the director of the $\mathrm{CSHeB}$, he has tried to establish an outstanding R\&D center with global competitiveness by providing on-site research facilities, formulating synergistic interconnection with interdisciplinary researchers, and promoting collaboration and cooperation with various industries, government departments, and international universities. He also plays a key role in promoting sustainable healthy building technologies academically by hosting international symposiums, seminars, and workshops. He acted as the president of the Acoustical Society of Korea (2005), the Korea Institute of Ecological Architecture and Environment (2007-2008), and currently acts as the President of the Korea Society of Lighting and Visual Environment and the vice-president of the International Society of the Built Environment. 